\title{
El costo de la justicia: Las costas en el Derecho procesal civil chileno y los modelos para su regulación
}

\section{The Cost of Justice: Costs And LAWyer's Fees in ChILEAN CiviL Procedure LAW AND tHe Models for ITS REGULATION}

\section{RESUMEN}

El artículo analiza críticamente la regulación de las costas personales en el Derecho procesal civil chileno, planteando aspectos que deben ser abordados de cara a una futura reforma al procedimiento civil chileno. En primer lugar, se examina el concepto de costas y su importancia en relación al acceso a la justicia. En segundo lugar, se analiza la distribución de las costas personales, contraponiendo la regla inglesa de "el que pierde paga" con la regla estadounidense sobre la materia. Posteriormente, se analiza la regulación procesal civil chilena, particularmente la definición de los "motivos plausibles para litigar", argumentando que no existen actualmente parámetros objetivos para la determinación de este último criterio. Adicionalmente, se formulan críticas a la determinación de las costas personales, al carecer nuestro sistema de una regla o criterios precisos para dicha determinación. Al respecto, se sugiere que los tribunales soliciten y revisen cuáles fueron los gastos en que efectivamente incurrió la parte vencedora en el juicio.

\section{PALABRAS CLAVE}

Costas, distribución de costas, proceso civil, acceso a la justicia.

\section{ABSTRACT}

The article critically analyzes the regulation of lawyer's fees in the Chilean Civil Procedure system, raising some issues that should be taken into account on a future reform of the Chilean civil procedure. First, the concept of litigation of costs and its relationship with access to justice is examined. Secondly, the allocation of lawyer's fees is analyzed, comparing the English "loser pays rule" with the American rule on the subject. Thirdly, the Chilean civil procedure rules are analyzed, particularly the definition of the "sound reasons to litigate" criterion, arguing that currently there are no objective parameters to apply this criterion. Additionally, the article advances some criticisms to the assessment of lawyer's fees, due to the lack of rules or criteria for its assessment. For this regard, it is suggested that courts should ask and review the real costs in which the winner party actually incurred during trial.

\section{KEYWORDS}

Lawyer's fees, allocation of fees, civil procedure, access to justice.

\section{Introducción}

El objetivo del presente trabajo es dilucidar la naturaleza jurídica que poseen las costas dentro del derecho procesal civil chileno, analizando al respecto las funciones que ellas pueden

\footnotetext{
* Profesor Asistente, Universidad Adolfo Ibáñez, Santiago, Chile. c.correa@uai.cl.

*** Profesor Asociado, Universidad Adolfo Ibáñez, Santiago, Chile. alberto.pino@uai.cl.
} 
desempeñar, los requisitos de procedencia de su imposición, y los criterios que permiten avaluar su cuantía en un caso concreto.

A nuestro juicio, se trata de una materia que no ha sido abordada con suficiente atención por parte de la doctrina chilena, a pesar de su evidente importancia práctica. La concepción que se tenga de la condena en costas, y su quantum, incidirá no solo en la conducta de las partes en un juicio específico, sino que -más relevante aún- trascenderá en aspectos generales vinculados al funcionamiento de la administración de justicia. A este respecto, la condena en costas se presenta como un instrumento en extremo sensible para los litigantes. Tal como se discutirá a lo largo del presente trabajo, su regulación y aplicación práctica podría disuadir la interposición de acciones temerarias, fomentar la proliferación de acciones infundadas ante una condena en costas inefectiva, incentivar una litigación incidentalista, afectar el derecho de las víctimas a una reparación integral (en el caso de demandas de responsabilidad civil), o incluso restringir el acceso a la justicia en aquellos casos en los cuales el riesgo de una alta condena en costas supere la probabilidad de éxito esperable de la acción intentada. Por otra parte, desde el punto de vista de la contratación internacional, se ha advertido que la regulación de las costas es una materia fundamental para la determinación de la jurisdicción a la que será sometido un contrato ${ }^{1}$.

La falta de estudios sobre la materia ha conducido a que no exista claridad en la jurisprudencia chilena respecto de los requisitos de procedencia de la condena en costas, siendo estos reemplazados en la práctica por criterios meramente intuitivos que permiten caso a caso determinar si el demandado tuvo o no "motivos plausibles para litigar". Asimismo, la ausencia de un tratamiento dogmático acabado ha privado a la judicatura de parámetros claros para la determinación del monto de la condena en costas.

Para alcanzar los objetivos recién trazados, el trabajo se estructura del siguiente modo: en una primera sección, daremos cuenta del concepto de costas a partir de la doctrina y jurisprudencia chilenas. Posteriormente, se analizan los sistemas de distribución de costas, teniendo en cuenta los modelos representados por la regla inglesa y la estadounidense. A continuación, describiremos la regulación legal de las costas en el proceso civil chileno, considerando los criterios para determinar la procedencia de dicha condena. Luego, analizaremos los parámetros para la avaluación de las costas personales. Finalmente, enunciamos las conclusiones e implicancias del trabajo realizado.

\section{El concepto de costas}

La doctrina chilena ha entendido históricamente las costas como "gastos del juicio", generados con motivo de este. En este sentido, Stoehrel las ha definido como aquellos "gastos que se originan durante una tramitación judicial y que son consecuencia directa de ella"2. En un sentido similar, Cortez y Palomo han definido recientemente el concepto de costas como "aquellas erogaciones económicas que corresponde efectuar a la parte que resulte vencida judicialmente y comprende todos los gastos causados u ocasionados por la sustanciación del proceso" ${ }^{\prime 3}$. Por su parte, Casarino ha centrado su definición en quién debe soportar las costas en un proceso, señalando al respecto que estas "son los gastos inmediatos y directos que origina una gestión judicial y que deben ser soportados por las partes en conformidad a la ley"4. Por último, la Corte Suprema las ha entendido derechamente como expensas directas de las partes, esto es como "los gastos en que deben incurrir las partes con motivo de la defensa de sus derechos en juicio" 5 .

\footnotetext{
${ }^{1}$ REIMANN (2012), p. 4.

2 STOEHREL (2007), p. 53. En el mismo sentido, Corte de Apelaciones de Temuco, Rol N 1053-2016, de 17 de octubre de 2016.

${ }^{3}$ CORTEZ y PALOMO (2018), p. 431.

${ }^{4}$ CASARINO (2005), p. 170.

${ }^{5}$ Corte Suprema, Rol N³3.290-1995, de 9 de julio de 1996.
} 
La uniformidad doctrinaria en torno al concepto de gastos del juicio, se diluye en una falta de claridad existente en Chile tanto en lo referido al origen de estas (gastos judiciales o gastos de defensa) como a los sujetos obligados a su pago (gastos en los que incurren directamente las partes, o bien gastos propios de la gestión judicial que deben ser soportados por las partes).

La legislación procesal civil chilena diferencia la determinación del sujeto obligado a pagar las costas del procedimiento para determinar la cuantía de estas. Respecto a esto último, la regulación vigente distingue entre costas personales y costas procesales, según cual sea el origen del gasto ${ }^{6}$. Costas procesales son, de conformidad al artículo 139 inc. $2^{\circ}$ del Código de Procedimiento Civil (en adelante $\mathrm{CPC}$ ) "Ias causadas en la formación del proceso y que corresponden a servicios estimados en los aranceles judiciales". Por su parte, las costas personales son, de acuerdo al inciso siguiente de la citada disposición "las provenientes de los honorarios de los abogados y demás personas que hayan intervenido en el negocio y de los defensores públicos en el caso del artículo 367 del Código Orgánico de Tribunales".

La fuente remota de la obligación que la ley impone a los litigantes de pagar las costas procesales de un juicio se encuentra contenida en el artículo $25 \mathrm{CPC}$, el cual dispone que "todo litigante está obligado a pagar a los oficiales de la administración de justicia los derechos que los aranceles judiciales les señalen para los servicios prestados en el proceso".

Asimismo, la regla que determina la distribución del pago de dichos aranceles se encuentra consagrada en el inciso segundo del citado artículo 25 del CPC, el cual señala que "cada parte pagará los derechos correspondientes a las diligencias que hayan solicitado y todas por cuotas iguales de las diligencias comunes". Como sabemos, estos gastos constituyen comúnmente costos asociados a la tramitación de un juicio, consistentes en la realización de diligencias y actuaciones vinculadas con el proceso, por parte de auxiliares de la administración de justicia (entre otros, notificaciones, honorarios por recepción de la prueba testimonial, o bien costos de inscripciones ante el Conservador de Bienes Raíces, etc.).

De este modo, como correctamente se ha sostenido", la primera parte del artículo 25 del CPC consagra el principio de la "anticipación de las costas", mediante el cual se establece que a lo largo del juicio son las partes quienes deberán anticipar el pago de las costas que se originen a lo largo del juicio a medida que estas se devenguen. El derecho a reembolso - propio de la condena en costas - surge, como veremos, posteriormente, una vez concluida la tramitación del proceso, recurso o incidente en cuya virtud se originaron dichos gastos.

Precisamente, la regla que permite vincular las disposiciones sobre las cargas pecuniarias que origina el proceso con la condena en costas, se encuentra contenida en el artículo 25 inciso $2^{\circ}$ parte final del CPC, disposición que establece que el pago que cada parte debe solventar, referido a los derechos de diligencias realizadas en juicio, se entenderá "sin perjuicio del reembolso al que haya lugar cuando por la ley o por resolución de los tribunales corresponda a otras personas hacer el pago". Dicha regla, sabemos, remite al ya mencionado artículo 139 inciso $2^{\circ}$ del CPC.

Del análisis de las disposiciones referidas, podemos sostener que el sistema procesal vigente entiende las costas procesales como verdaderas reglas de reintegro o restitución de gastos, generalmente aranceles, solventados por la parte vencedora a lo largo del juicio. De este modo, la obligación que surge durante el transcurso del juicio referida al pago de aranceles judiciales y cuya carga debe soportar el solicitante apenas estos se devenguen, puede finalmente ser asumida íntegramente por el litigante derrotado, generándose en estos casos una obligación de reintegro a favor de quien obtuvo sentencia favorable en juicio.

\footnotetext{
${ }^{6}$ CORTEZ Y PALOMO (2018), p. 432.

${ }^{7}$ CORTEZ Y PALOMO (2018), p. 433.
} 


\subsection{El fundamento legal de la obligación de pagar costas}

Desde el punto de vista del derecho de las obligaciones, el pago de las costas constituye una obligación civil cuyo origen es la ley, conforme la configuración de las fuentes de las obligaciones del artículo 1437 del Código Civil ${ }^{8}$.

Ahora bien, la condena en costas en un caso concreto, se origina siempre mediando una resolución judicial que así lo establece. La fuente general de dicha obligación, en lo referido al juicio ordinario, se encuentra contenida en el artículo 144 del CPC, el cual establece que "La parte que sea vencida totalmente en un juicio o en un incidente, será condenada al pago de las costas". Por su parte, tratándose del juicio ejecutivo, la fuente de la obligación surge a partir del artículo 471 del CPC, el cual establece de forma similar que las costas son de cargo del ejecutado si la sentencia definitiva ordena seguir adelante con la ejecución, mientras que serán de cargo del ejecutante si se absuelve al ejecutado.

Es por su origen netamente procesal que el nacimiento y cuantía de la obligación del pago de costas nace con el proceso y se encuentra además condicionado en su procedencia, monto y naturaleza, al desarrollo y resultado del mismo ${ }^{9}$. De este modo, la obligación consistente en el pago de costas, solo se originará y será susceptible de ser determinada en cuanto a su alcance y monto al finalizar el proceso, o concluida aquella actuación procesal que le da origen. La obligación de pagar las costas del proceso será entonces indeterminada al comienzo del litigio, tanto en lo referido al monto que esta alcanzará como, asimismo, respecto de la parte que será finalmente la obligada a su pago ${ }^{10}$.

Desde el punto de vista del derecho civil patrimonial, las costas forman parte de los gastos que ocasiona el pago de la obligación principal, en virtud de lo dispuesto en el artículo 1571 del Código Civil ${ }^{11}$. Dicha norma establece la regla general según la cual los gastos que origine el pago de la obligación son de cargo del deudor, incluyéndose en estos las costas, sin perjuicio de lo estipulado por las partes y de lo que el juez ordene respecto al pago de estas. Por lo tanto, la determinación de la condena en costas por parte del tribunal regirá sin perjuicio de lo que hayan dispuesto las partes, debiendo el juez resolver para tal efecto en base a lo dispuesto en los artículos 144 y siguientes o en juicio ejecutivo por el artículo 471, ambos del CPC.

Por otra parte, desde el punto de vista de la responsabilidad extracontractual, la condena en costas puede cumplir un rol fundamental especialmente en aquellos casos en los cuales los daños causados a la víctima resultan poco significativos, o cuando el demandante solo solicita el cese de la actividad ilícita sin exigir indemnización alguna ${ }^{12}$. En este tipo de casos, la condena en costas se vuelve necesaria para permitir que el demandante pueda ejercer sus derechos de manera eficaz, sin perjuicio de que una eventual indemnización (en caso que sea procedente) resulte a la larga incluso inferior a los costos en que se incurre para ejercitar una acción.

Asimismo, la obligación legal, consistente en la imposición de una condena en costas al litigante completamente derrotado en juicio, no depende para su nacimiento de la voluntad de las partes litigantes. Si bien lo usual será que demandante y demandado soliciten, como corolario a sus peticiones principales, que se condene en costas a la contraria, lo cierto es que la declaración judicial que asigna el pago de costas a uno de los litigantes puede generarse aún sin una solicitud formal de partes. Tal como se ha fallado, el tribunal que así resuelva no incurrirá en el vicio de ultrapetita ${ }^{13}$. Dicha conclusión se desprende fundamentalmente del tenor literal

\footnotetext{
${ }^{8} \mathrm{~A}$ menos que la obligación tenga un origen contractual, en cuyo caso considerando las costas como gastos del pago, el origen de la obligación sería la voluntad de las partes.

${ }^{9}$ BAUMBACH et al. (2018), p. 306.

${ }^{10}$ BAUMBACH et al. (2018), p. 911.

${ }^{11}$ ABELIUK (2014), pp. 744-745.

12 Por ejemplo, frente a una vulneración a la propiedad intelectual, la víctima puede solicitar "el cese de la actividad ilícita del infractor" (artículo 85 B letra a) de la Ley N 17.336, de 1970), o el ejercicio de la acción de reparación del daño ambiental del artículo 53 de la Ley $\mathrm{N}^{\circ} 19.300$, de 1994.

${ }^{13}$ Corte Suprema, 2 de junio de 1924 y Corte Suprema, 22 de octubre de 1926.
} 
del artículo 144 del CPC $^{14}$, disposición que establece imperativamente un pronunciamiento sobre la condena en costas al utilizar la expresión "será condenada", en desmedro de una expresión facultativa como por ejemplo la utilizada en el artículo 145 del mismo cuerpo legal, al tratar el legislador la eximición de condena en costas en segunda instancia: "podrá el tribunal".

Distinta será la respuesta en lo referido al cumplimiento forzado de la obligación generada a partir de una condena en costas. A este respecto, será desde luego, facultad exclusiva del acreedor de dichas costas exigir su cumplimiento compulsivo. Respecto a este punto, la obligación derivada de una condena en costas no se distingue de cualquier otra obligación civil de carácter patrimonial.

\subsection{La función que desempeña la condena en costas en el proceso civil}

Respecto a la función desempeñada por la condena en costas, se ha discutido si esta obedece a una sanción procesal o corresponde a una medida de carácter meramente resarcitorio.

Sustentando un carácter meramente resarcitorio de la condena en costas, Carreta ha entendido las costas como indemnizaciones compensatorias de los gastos originados en el proceso ${ }^{15}$. Como advierte Chiovenda, la concepción de las costas como resarcimiento prevalecía en la doctrina y jurisprudencia francesas, concibiendo la condena en costas como "restitución de desembolsos realizados y reparación de daños sufridos" 16 . Pareciera ser también el criterio dominante para el ámbito del arbitraje en Chile ${ }^{17}$ y como ya se mencionó, la posición mayoritaria de la doctrina nacional.

La postura opuesta, que entiende la condena en costas como una verdadera sanción procesal, se encuentra enunciada ya en el Mensaje del Código de Procedimiento Civil, oportunidad en la cual el legislador estableció que "para que la condena en costas sea un correctivo eficaz, habrá de imponerse en todo caso de pérdida, salvo que circunstancias muy calificadas hagan necesaria una declaración expresa del tribunal en el sentido contrario"18. Desde esta perspectiva, se concibe a la condena en costas como una herramienta dirigida a castigar a una de las partes cuando "el uso del derecho a litigar se convierte en abuso"19.

En el mismo sentido se ha manifestado Rodríguez, para quien la condena en costas se trataría de una verdadera sanción civil contra una aventura judicial sin ningún fundamento ${ }^{20}$. De modo similar, para Romero la condena en costas cumpliría una doble función, la cual considera los aspectos antes mencionados: se trataría de un mecanismo sancionador o bien resarcitorio, que se aplica al litigante perdedor ${ }^{21}$.

La Corte Suprema ha sostenido de manera un tanto ambigua, que la regla sobre condena en costas contenida en el artículo $146 \mathrm{CPC}$ "no tiene el carácter de decisoria litis sino que constituye una regla de carácter económico o disciplinario (...)"22. Siguiendo esta línea, el máximo tribunal ha señalado que "la condenación en costas es una medida de carácter económico (...) no está subordinada a las peticiones de las partes, sino al criterio que se forma el juez con

\footnotetext{
${ }^{14}$ En este sentido: CORTEZ y PALOMO (2018), p. 435.

${ }^{15}$ CARRETA (2008), p. 109.

${ }^{16}$ CHIOVENDA (2004), p. 100.

${ }^{17}$ Al respecto, puede consultarse el artículo 44 del Reglamento Procesal de Arbitraje del Centro de Arbitraje y Mediación de la Cámara de Comercio de Santiago: "El Tribunal Arbitral deberá fijar las costas procesales y personales del arbitraje, a más tardar en la sentencia definitiva, las cuales representarán el reembolso de los gastos efectivamente incurridos por las partes que se encontraren acreditados en el proceso" (énfasis agregado).

${ }_{18}$ Siguiendo expresamente este concepto como fundamento de la condena en costas, véase Corte de Apelaciones de Concepción, Rol N¹521-2010, de 23 de marzo de 2011.

${ }^{19}$ CHIOVENDA (2004), p. 99.

${ }^{20}$ RODRÍGUEZ (2013).

${ }^{21}$ ROMERO (2017), p. 231.

${ }^{22}$ Corte Suprema, Rol N³319-2005, de 17 de enero de 2007; Corte Suprema, 16 octubre 1970.
} 
respecto a los fundamentos que hayan tenido estas personas para litigar" ${ }^{\prime 23}$. Por su parte, la Corte de Apelaciones de Temuco ha señalado en este sentido que

si bien es cierto, la condena en costas tiene por objeto sancionar la actuación del litigante que ha sido vencido en juicio, no lo es menos que también persigue satisfacer pecuniariamente la labor desplegada por los abogados en la defensa de los intereses de sus clientes ${ }^{24}$.

De este modo, pareciera ser dominante la idea según la cual las costas no solo cumplen una función propia de la justicia correctiva o conmutativa, en términos de restituir a las partes los gastos en que estas hayan incurrido como consecuencia de accionar los órganos jurisdiccionales para el ejercicio de una pretensión, sino que también se ha reconocido una función retributiva o sancionatoria en las costas. Desde esta perspectiva, la regulación y aplicación práctica de la condena en costas debiera tener el objetivo de evitar o al menos disminuir los costos de la litigación temeraria por parte de los abogados litigantes, disuadiendo así la interposición de demandas frívolas, esto es de aquellas que carecen de mérito alguno y que son interpuestas con el solo objetivo de presionar a la contraparte para obtener un acuerdo extrajudicial ${ }^{25}$.

La necesidad práctica de desincentivar acciones temerarias es evidente y no requiere de mayor análisis. A este respecto, basta con señalar - como se ha sostenido- que estas demandas son problemáticas desde el punto de vista de la eficiencia, forzando a las partes y al sistema a incurrir en gastos innecesarios. Asimismo, la proliferación de acciones infundadas resulta compleja desde el punto de vista de la justicia contractual, toda vez que una persona puede verse obligada a consentir bajo circunstancias apremiantes y oportunistas alguna salida rápida al conflicto ${ }^{26}$, sin encontrarse jurídicamente obligada a ello. Como veremos más adelante, parte de la regulación chilena de las costas atiende a este propósito.

Por otra parte, y como esbozamos precedentemente, desde un punto de vista económico, las costas se erigen como un factor relevante para determinar los costos de la litigación. Es precisamente a partir de dicha función, que parte de la literatura propia del análisis económico del Derecho se ha preocupado de analizar la configuración más eficiente de regulación de las costas, de modo tal de disminuir por medio de estas, los costos totales de la litigación ${ }^{27}$.

A partir de dicha finalidad, resulta interesante tomar en cuenta los estímulos y desincentivos que a este respecto otorga la regulación de las costas en un sistema concreto. Por ejemplo, en Estados Unidos, la Regla 68 de las Reglas Federales de Procedimiento Civil [Federal Rules of Civil Procedure] establece que en aquellos casos en los cuales el demandado realiza una oferta de acuerdo extrajudicial durante el transcurso del juicio, si el demandante rechaza la oferta y posteriormente obtiene una sentencia menos favorable que la oferta de acuerdo rechazada, el demandante deberá hacerse cargo de todas las costas en que haya incurrido en el juicio, no obstante ser la parte -al menos parcialmente- vencedora ${ }^{28}$. Una regla similar puede encontrarse en el derecho inglés ${ }^{29}$. Si se sigue la corriente actual que parece incentivar los

\footnotetext{
${ }^{23}$ Corte Suprema, 4 diciembre 1939; Corte Suprema, 14 enero 1947; Corte Suprema, 11 junio 1954; Corte Suprema, 14 septiembre 1954; Corte Suprema, 20 octubre 195; Corte Suprema, 10 agosto 1959; Corte Suprema, 16 diciembre 1960; Corte Suprema, 30 septiembre 1966.

${ }^{24}$ Corte de Apelaciones de Temuco, Rol N 513-2016, de 10 de junio de 2016.

${ }^{25}$ KATZ (1990), p. 3.

${ }^{26}$ KATZ (1990), pp. 3-4. Si el objetivo de la demanda es obtener el consentimiento de la contraparte para la celebración de un contrato, resulta posible plantear la existencia de un vicio de fuerza para la invalidación de dicho acto, en atención a las circunstancias en las cuales se amenaza con ejercer la acción (sin perjuicio que se trate de una amenaza prima facie lícita). BARROS (2017), p. 293.

27 Véase por ejemplo POSNER (2007), pp. 610-622; SPIER (2007), pp. 300-305.

${ }^{28} \mathrm{Si}$ bien ello ocurre normalmente respecto de los honorarios de los abogados en Estados Unidos, ello puede incidir negativamente para que el demandante pueda cubrir otras costas procesales. Sobre el análisis económico de esta regla véase entre otros PRIEST (1982) y ANDERSON (1994).

${ }^{29}$ Civil Procedure Rules, de 1998, § 36. Esta regla establece que el demandante o demandado que rechace una oferta de acuerdo estará sujeto a tener que soportar las consecuencias adversas de las costas. Sobre la aplicación de esta regla en detalle, véase ANDREWS (2019), pp. 541-546.
} 
acuerdos extrajudiciales y la mediación en los procedimientos civiles contenciosos, debiera considerarse por el legislador una regla similar a esta ${ }^{30}$.

En suma, se advierte que la condena en costas cumple una doble función en el proceso civil: por una parte, permite resarcir a la parte vencedora los gastos en que haya incurrido como consecuencia del litigio. Por otra parte, la condena en costas asimismo cumple una función regulatoria de la litigación, en tanto desincentiva o sanciona la litigación frívola o temeraria, disminuyendo de este modo los costos totales de los pleitos civiles.

\subsection{La distribución de las costas y el acceso a la justicia}

Las costas también pueden comprenderse bajo el prisma de principios de justicia distributiva, bajo la famosa analogía de Finnis del juez como encargado de la distribución de un bien común (la lis inter partes) entre el demandante y el demandado ${ }^{31}$. Bajo este prisma, la pregunta respecto de la regulación de las costas es la siguiente: ¿debe el demandado vencido ser obligado a pagar las costas personales del demandante (regla conocida como "el que pierde paga" [loser-pays rules]), o por el contrario, cada una de las partes debe hacerse cargo de sus propias costas, independiente del resultado?

La decisión, desde luego, será determinante desde el punto de vista del acceso a la justicia, ya que la regla "el que pierde paga" le asegura a cualquier demandante la posibilidad de acudir a la justicia, sin que los costos en que incurra para ejercer sus derechos sean en último término obstáculo para ello.

Tradicionalmente se ha entendido que los gastos propios de la función llevada a cabo por los tribunales deberán ser soportados por el Estado. La gratuidad en el ejercicio de la función jurisdiccional, se sostiene, constituye una de las bases fundamentales de la organización de los tribunales ${ }^{32}$, la cual permite a los ciudadanos recurrir ante un órgano imparcial para la resolución de los conflictos de naturaleza jurisdiccional. La garantía de gratuidad, permite asegurar la inexistencia de barreras que impidan ex ante el reconocimiento de una determinada pretensión ante los tribunales ${ }^{33}$, fomentando con ello la igualdad de las personas ante la ley y privilegiando asimismo las vías institucionales de resolución de controversias. Lo anterior pugna, sin embargo, con los recursos limitados que el Estado puede racionalmente destinar a la administración de justicia. En este sentido, algunos autores en Chile han planteado que debe matizarse la gratuidad mediante el establecimiento de tasas judiciales a la litigación ${ }^{34}$.

Ahora bien, desde el punto de vista exclusivamente de la regulación de las costas, en un mundo donde los bienes son escasos, la gratuidad "sin consecuencia alguna" en el ejercicio de la función jurisdiccional podría llevar al extremo de fomentar el ejercicio temerario de acciones y defensas, a sabiendas que actuaciones carentes de fundamentos no tendrán consecuencia alguna para quien las ejerza. La impunidad fomenta así el actuar del litigante temerario. Por otro lado, los costos de una administración de justicia sin consecuencias, incidirán asimismo en los ciudadanos, quienes deberán soportar el costo de verse inmersos en procesos carentes de fundamento, tolerando los costos de tiempo y pecuniarios que la defensa de sus intereses en juicio suponga. Lo anterior no parece ser razonable. Efectivamente, la amenaza de una efectiva condena en costas al final del proceso debiese - a lo menos- disuadir la proliferación de procesos carentes de seriedad; el riesgo de tener que pagar los gastos frenará en gran parte la manía de litigar ${ }^{35}$. De no ser así, los juicios se multiplicarían indefinidamente por la ausencia de

\footnotetext{
${ }^{30}$ Esta al menos parece ser la tendencia impulsada recientemente por la Comisión creada por el Ministerio de Justicia en el marco de la reforma al proceso civil.

${ }^{31}$ FINNIS (2000), p. 208.

${ }^{32}$ CASARINO (2005), p. 170.

${ }^{33}$ NÚÑEZ y PÉREZ (2013), p. 101.

${ }^{34}$ MERY (2010); VARGAS et al. (2001). En contra, NÚÑEZ y CARRASCO (2015).

${ }^{35}$ CASARINO (2005), p. 170.
} 
toda sanción, imponiéndose finalmente a la colectividad las consecuencias de un hecho imputable exclusivamente a los litigantes ${ }^{36}$.

El equilibrio que rodea a una eficiente condena en costas es frágil. Si bien, como se sostuvo en esta sección, una efectiva condena en costas constituye un freno frente a la litigación temeraria, una práctica excesivamente severa podría desincentivar la interposición de acciones debidamente justificadas por parte de personas de escasos recursos. La regulación y determinación de la condena en costas entonces, no debiese constituirse como un factor disuasivo que limite el ejercicio de acciones justas en sede jurisdiccional.

\section{3. ¿Quién debe soportar las costas personales?}

\subsection{La regla estadounidense versus la regla inglesa ${ }^{37}$}

Históricamente, se han propuesto fundamentalmente tres modelos de regulación de la condena en costas, en lo referido a la distribución del pago de estas ${ }^{38}$. En un primer modelo, se planteó como regla de distribución de las costas, el que cada litigante, sea vencedor o vencido, soporte las costas causadas en la instancia. Posteriormente, dicho mecanismo evolucionó a una regulación en la cual, la condición que imponía una condena en costas era la mala fe del litigante vencido. Más tarde, y fundamentalmente a partir de la dificultad que encierra la acreditación de la mala fe del litigante, se originó un modelo en el cual la condena en costas se imponía ante la condena absoluta o incondicionada del litigante vencido.

Actualmente, esta última regla se conoce con el nombre de "el que pierde que paga" o regla inglesa, la cual predomina en la mayoría de los sistemas jurídicos. Esta se contrapone a la regla imperante en los Estados Unidos ("la regla estadounidense"), según la cual cada parte debe cubrir sus costas personales, independiente del resultado del juicio. Lo cierto es que los sistemas jurídicos en general no contemplan regímenes puros basados exclusivamente en alguna de estas reglas, ni siquiera el propio sistema estadounidense o el inglés ${ }^{39}$. En este sentido, algunos prefieren cambiar la terminología por reglas de indemnidad, las cuales permiten recuperar los costos de litigación a la parte vencedora, y reglas de no-indemnidad, según las cuales cada parte debe soportar sus propios $\operatorname{costos}^{40}$.

La regla estadounidense fue articulada por la Corte Suprema de dicho país en el caso Alyeska Pipeline Service Co. vs. Wilderness Society, ${ }^{41}$ en el cual la Corte estableció que la parte vencedora no puede recuperar las costas personales en ausencia de alguna ley expresa o algún precedente judicial que constituya una excepción a la regla. Se ha sostenido que el fundamento general de la referida regla de distribución de costas estadounidense reside en facilitar el acceso a la justicia para personas de escasos recursos y otros sujetos adversos al riesgo ${ }^{42}$. Como explica la Corte Suprema,

dado que la litigación es al menos incierta, uno no debiera ser penalizado por tan solo defenderse o interponer una demanda (...). Los pobres pueden ser disuadidos de ejercer acciones para reivindicar sus derechos si la pena de ser derrotado incluye cubrir los costos de los abogados de la contraparte $^{43}$.

\footnotetext{
${ }^{36}$ En el mismo sentido, STOEHREI (2007), p. 53.

${ }^{37}$ Se contrasta para el presente análisis estos dos sistemas porque ellos han sido tradicionalmente contrapuestos por la literat ura, sin perjuicio de las referencias que se realicen a otros sistemas de derecho continental.

${ }^{38}$ CHIOVENDA (2004), p. 97.

39 Un panorama comparado general en HODGES (2010)

40 MAXEINER (2010), pp. 197-198. Para efectos de mayor claridad, seguiremos aquí utilizando la denominación de regla estadounidense, advirtiéndose que no es una denominación del todo precisa.

${ }^{41}$ Corte Suprema de Estados Unidos, 421 U.S. 240 (1975), de 12 de mayo de 1975.

${ }^{42}$ VARGO (1993), pp. 1593-1594.

${ }^{43}$ Fleishmann Distilling Corp. vs. Maier Brewing Co., Corte Suprema de Estados Unidos, 386 U.S. 714, 718 (1967), de 8 de mayo de 1967.
} 
Más aún, algunos jueces han llegado incluso a sostener que esta regla representa un verdadero ideal democrático, vinculado al derecho a ser oído ${ }^{44}$.

La regla estadounidense suele ser criticada por incentivar demandas especulativas sin fundamentos, o que solo tienen el propósito de perjudicar o presionar a la contraparte ${ }^{45}$. Sin embargo, la literatura del análisis económico del derecho controvierte esta afirmación, señalando que la regla "el que pierde paga" tiende a aumentar los costos totales de la litigación ${ }^{46}$. La razón principal para llegar a esta conclusión se basa en que dicha regla aumenta los valores en juego del litigio, de modo tal, que el sistema en este caso otorga mayores incentivos a las partes para que ellas inviertan más en la contratación de los servicios legales, con el propósito de aumentar sus probabilidades de vencer en el juicio, generando un sistema más costoso en el agregado. También se critica la regla bajo el principio de la reparación integral del daño de la responsabilidad civil, sosteniendo que la víctima de un ilícito debiera tener derecho a ser reparada íntegramente, incluyendo las costas personales en que deba incurrir para el ejercicio de la acción ${ }^{47}$. Y particularmente en el ámbito de la responsabilidad civil extracontractual, se critica la regla por la proliferación de demandas en Estados Unidos bajo la expectativa que genera en los abogados los contingent fees o pactos de cuota litis ${ }^{48}$.

Ahora bien, se trata de una regla que, como se adelantó, contiene importantes excepciones. La principal de ellas es la existencia de una ley que expresamente le otorgue a la parte vencedora el derecho de cobrar las costas personales de la parte contraria. El mejor ejemplo de ello es la Civil Rights Attorney's Fees Act de 1976, que permite al demandante que ejerce una acción amparada por legislación que protege derechos civiles, recuperar las costas personales en el evento de obtener una decisión favorable sobre alguna de las pretensiones significativas de la demanda ${ }^{49}$. Ello ha contribuido a promover que las partes invoquen alguna pretensión relacionada con derechos civiles en litigios de diversa índole ${ }^{50}$. El otro grupo de excepciones a la regla se constituye por un conjunto numeroso de precedentes judiciales que establecen excepciones particulares, pudiendo agruparse en cuatro categorías: el fondo común, el beneficio común, el desacato, y la mala $\mathrm{fe}^{51}$. Particularmente interesante para los efectos de este trabajo resulta la última de estas excepciones: la excepción de mala fe. Esta excepción permite condenar en costas a un litigante que lleva a cabo una demanda o defensa "frívola", usualmente definida como carente de racionalidad argumentativa ${ }^{52}$. Ello puede ser procedente respecto del caso completo o tan solo una parte de él. Podemos apreciar entonces que la regla estadounidense, aunque parte de la base que cada litigante debe hacerse cargo de sus propias costas personales, establece una regla que sanciona la litigación frívola o de mala fe, con lo cual la condena en costas pasa finalmente a desempeñar una función sancionatoria.

Un matiz similar puede encontrarse en el derecho inglés donde predomina la regla "el que pierde paga". Debe advertirse en primer lugar que la regla ha sido ampliamente criticada por la

\footnotetext{
${ }^{44}$ Así, por ejemplo, en Mihalik vs. Pro Arts Inc., Corte de Apelaciones del Sexto Circuito, 851 F. 2 d 790 (6th Cir. 1988), de 7 de julio de 1988.

${ }^{45}$ Véase por ejemplo KUENZEL (1963) y GREENBERGER (1964), quienes proponen adoptar en Estados Unidos la regla inglesa del que pierde paga.

${ }^{46}$ KATZ (1987), pp. 144-145.

${ }^{47}$ EHRENZWEIG (1966), p. 792.

${ }^{48}$ GOLDBERG et al. (2016), pp. 20-21. El examen de este tipo de acuerdos escapa a los objetivos de este trabajo. Sin embargo, se advierte una tendencia creciente en Europa de permitir estos acuerdos que tradicionalmente estaban prohibidos en sistemas sometidos a la regla inglesa. Sobre esto, véase un interesante estudio en BAUMANN y FRIEHE (2012).

${ }^{49} 42$ U.S.C. $\S 1988$, de 2006. Este tipo de reglas se conocen con el nombre de "one-way fee shifting statutes", puesto que solo permiten recuperar las costas a los demandantes que obtienen sentencias favorables, pero nunca a los demandados.

${ }^{50}$ HERR et al. (2013), p. 810.

${ }^{51}$ HERR et al. (2013), pp. 814 y ss. La excepción del fondo común se configura en aquellos casos en los cuales el demandante obtiene a su favor un fondo común con otras personas que no formaron parte del litigio, en cuyo caso las costas personales deben distribuirse entre todos los beneficiarios del fondo común. La excepción del beneficio común es similar a la anterior, pero sin que se requiera la constitución de un fondo común, siendo suficiente que se otorgue un beneficio común. La excepción del desacato permite recuperar las costas personales de la contraparte en contra de la cual se haya decretado una orden de desacato. La excepción de la mala fe permite a un litigante recuperar costas personales de su contraparte si esta ha demandado de mala fe o se ha defendido de mala fe.

${ }^{52}$ HERR et al. (2013), p. 817.
} 
doctrina y la jurisprudencia, debido a que los costos de litigación en el Reino Unido se mantienen altos $^{53}$. En la aplicación de la regla, los tribunales tienen la facultad de aplicar la regla con discreción, de modo tal que pueden determinar el monto a pagar por las costas, y pueden decidir además a partir de qué etapa de la litigación se pagarán las costas. El juez de la Corte de Apelaciones Lord Woolf expresó esta idea con mucha claridad en el caso AEI Rediffusion Music $L t d v$. Phonographic Performance $L t d(1999)^{54}$, señalando que imponer estrictamente la regla del que pierde paga

incentiva a que los litigantes aumenten los costos de la litigación, ya que desincentiva a los litigantes a ser selectivos sobre los argumentos que plantean. Si usted recupera todos sus costos en la medida que gane, usted tiene un incentivo para no dejar una piedra sin remover para ganar.

Por otra parte, las reglas pertinentes del Civil Procedure Rules de 1998 ( $\$ \S 44.13$ a 44.16) establecen que tratándose de demandas por indemnización de perjuicios correspondientes a lesiones personales, el demandante normalmente no tendrá que cubrir las costas del demandado en caso que no obtenga sentencia a su favor, aunque el demandado sí deberá cubrir las costas del demandante en el evento de una sentencia condenatoria. El objetivo de esta excepción es privilegiar a este tipo de víctimas, removiendo una posible barrera que podría obstaculizar el acceso a la justicia para estas personas (por el riesgo de tener que cubrir las costas del demandado en caso de no obtener una sentencia favorable) ${ }^{55}$. Sin embargo, la excepción no se aplica en el caso de demandas temerarias o injustificadas (demandas "fundamentalmente deshonestas"), o en demandas que surjan a partir de un "abuso del proceso" 56.

Por último, cabe señalar que la regla general de costas establecida para la parte vencedora en juicio solo cubre los costos "estándares" en que haya incurrido, lo cual somete la determinación que hace el tribunal a un estándar de proporcionalidad ${ }^{57}$. Sin embargo, los tribunales pueden decretar una condena en costas que cubrirá costos adicionales a los costos estándares, no sometidos al estándar de proporcionalidad. Estos costos, llamados "indemnity costs", son decretados en el caso que la parte que pierde haya tenido una conducta no razonable, indicándose como ejemplo de ello la interposición de una demanda de forma especialmente agresiva, que no tenga fundamento plausible, que sea oportunista en su naturaleza y que las peticiones al tribunal sean exageradas ${ }^{58}$. Nos encontramos aquí nuevamente con una función punitiva o sancionatoria que pasan a desempeñar las costas.

En suma, puede apreciarse que ambos modelos, tanto el estadounidense como el inglés, contienen una serie de sofisticadas reglas que parten de principios contrapuestos, pero que buscan alcanzar los mismos objetivos de, por una parte, asegurar el acceso a la justicia y el resarcimiento de los costos en que ha incurrido la parte vencedora, y por la otra, a evitar que los litigantes utilicen el proceso civil de forma abusiva e ineficiente, sancionando mediante la condena en costas conductas frívolas o que carecen de fundamento racional de las partes.

\footnotetext{
${ }^{53}$ Véase, entre otros, ANDREWS (2019), p. 524 y PEYSNER (2009), pp. 160-163. La propia Corte Suprema lo advierte recientemente en Coventry v. Lawrence, Corte Suprema del Reino Unido, [2014] UKSC 46, de 22 de julio de 2015, [36]: "sería un error para esta Corte no expresar su preocupación grave sobre los costos de base en este caso, y expresar la esperanza de que quienes son responsables de la justicia civil en Inglaterra y Gales estén considerando cuáles pasos adicionales podrían tomarse para asegurar un mejor acceso a la justicia" (Lord Neuberger).

${ }^{54}$ Corte de Apelaciones de Inglaterra y Gales, de 19 de febrero de 1999, [1999] 1 WLR 1507, 1523.

${ }^{55}$ ANDREWS (2019), p. 527.

${ }^{56}$ Civil Procedure Rules, de 1998, §44.15.

${ }^{57}$ Civil Procedure Rules, de 1998, §44.3.

${ }^{58}$ Excalibur Ventures LLC v Texas Keystone Inc. (No 2), High Court de Inglaterra y Gales, de 18 de noviembre de 2016, [2016] EWCA Civ $114,[8]$ y ss.
} 


\subsection{La regla imperante en Chile: El que pierde paga como criterio binario}

Las normas sobre imputación del pago de costas se encuentran contenidas en los artículos 138 y ss. del CPC. A este respecto, la regla general para el juicio ordinario se encuentra expresada en el artículo 144 inc. $1^{\circ}$ de dicho cuerpo legal, disposición que establece que la parte que sea vencida totalmente en un juicio o en un incidente, será condenada al pago de las costas. Así las cosas, el legislador chileno ha establecido como criterio de determinación de la parte que deberá soportar el pago de las costas el vencimiento tota 159 , ya sea en el proceso, ya sea en un incidente o recurso aislado. Podemos entender que una parte ha sido totalmente vencida cuando las pretensiones de la contraria, ante las cuales presentaba una resistencia, fueron completamente acogidas por el tribunal ${ }^{60}$. Vencido, sostenía Chiovenda, es aquel en contra del cual se declara el derecho o se dicta la resolución judicial, ya se trate del demandado contra quien se dirige la demanda, o bien del actor contra quien la demanda se declara infundada ${ }^{61}$. Concordante con dicha interpretación, la Corte de Apelaciones de Concepción ha sostenido que "la expresión 'vencida totalmente' implica que el demandante obtuvo en la decisión del litigio, todo lo que pidió en la demanda" 62 .

Como sostenía Couture, desde que el proceso tiene un costo, este debe recaer sobre alguno de los litigantes; lo lógico a este respecto, es que recaiga sobre el litigante que no tiene razón ${ }^{63}$. De este modo, en materia de costas, prosigue dicho autor, el principio de que el que pierde paga constituye un precepto de responsabilidad análogo al de la responsabilidad civil, según el cual el que rompe paga ${ }^{64}$. Puede hablarse así de una especie de responsabilidad estricta o una obligación de resultado en la doctrina de derecho civil ${ }^{65}$. Prescindiendo de toda consideración subjetiva, lo que se tiene en cuenta es, solamente, la circunstancia de la derrota ${ }^{66}$.

La mencionada regla procesal del "vencimiento total" constituye una regla binaria: quien es totalmente derrotado en juicio, deberá asumir —salvo que haya tenido motivos plausibles para litigar - la totalidad de los costos del juicio. A nuestro entender, esta regla de todo o nada es defectuosa. En efecto, si reconocemos a la condena en costas un efecto disuasivo, como se expuso supra, debiese ser la distribución de dicha condena entre las partes susceptible de graduación en virtud del porcentaje de éxito de los litigantes en juicio ${ }^{67}$. Pese a no haber sido totalmente derrotada una de las partes en juicio, por ejemplo al haberse acogido parcialmente una pretensión o defensa accesoria de escasa entidad, debiese razonablemente imponerse una sanción en costas a este litigante (no totalmente) vencido, graduada en virtud de su derrota parcial, que permita cumplir con fines disuasivos y restitutorios que la eximición de la condena no es capaz de satisfacer. En estos casos, además, el quantum de la condena debiese ser inferior a aquel que recibirá aquel litigante totalmente vencido en juicio ${ }^{68}$. Dicha idea no resulta del todo ajena a nuestra regulación vigente. En efecto, el mismo CPC establece para las costas en el juicio

\footnotetext{
${ }^{59}$ Sobre el contenido del vencimiento total en relación a la naturaleza de las peticiones invocadas en juicio, véase CORTEZ y PALOMO (2018), p. 436.

${ }^{60}$ La eximición de la condena en costas por motivo plausible para litigar no se aplica al juicio ejecutivo, en el cual la regla establecida en el artículo 471 del CPC establece reglas estrictas de imposición o eximición de condena en costas, atendiendo como único criterio si la sentencia definitiva acoge o no las excepciones opuestas por el ejecutado. Al respecto véase Corte de Apelaciones de San Miguel, Rol N 1287-2012, de 24 de enero de 2013.

${ }^{61}$ CHIOVENDA (2004), p. 147.

${ }^{62}$ Corte de Apelaciones de Concepción, Rol N 1144-2016, de 9 de diciembre de 2016, y Corte de Apelaciones de Concepción, Rol N 816-2016, de 20 de septiembre de 2016.

${ }^{63}$ COUTURE (2003), p. 235.

${ }^{64}$ COUTURE (2003), p. 235.

${ }^{65}$ ANDREWS (2019), p. 525

${ }^{66}$ COUTURE (2003), p. 236.

${ }^{67}$ La mayoría de los sistemas jurídicos suele adoptar la distribución de las costas en este tipo de casos, ya sea en el derecho legislado o en la jurisprudencia. REIMANN (2012), pp. 18-19.

${ }^{68}$ Una regla en el mismo sentido de lo que proponemos puede encontrarse en la regulación inglesa de las Civil Procedure Rules, de $1998, \S 44.2(4)$ (b) (permite al tribunal determinar discrecionalmente la cuantía de las costas sobre la base de un vencimiento parcial de alguna de las partes).
} 
ejecutivo, en el artículo 471 inc. $2^{\circ}$ que si se admiten una o más excepciones, las costas se distribuyen proporcionalmente.

Asimismo, el proyecto de ley que establece un Código Procesal Civil, actualmente pendiente de tramitación legislativa, si bien mantiene en su artículo 41 como criterio general de imposición de condena en costas el dogma del "vencimiento total", permite a continuación flexibilizar dicha regla al permitir a los tribunales imponer igualmente el pago de costas " $a$ la parte cuyas peticiones hubieren sido substancialmente rechazadas".

Soluciones como las anteriormente descritas permiten dotar de una mayor flexibilidad a los tribunales al momento de imponer una condena en costas, más allá del "total vencimiento en juicio" impuesto como criterio por parte del artículo 144 inc. $1^{\circ} \mathrm{CPC}$, superando de esta forma los márgenes estrechos de dicha regla que impiden que cumpla cabalmente las finalidades esperadas.

\subsection{La válvula de control: Los motivos plausibles para litigar}

De acuerdo a la legislación vigente, aun cuando una parte haya sido totalmente vencida en juicio, el legislador -artículo 144 inc. $1^{\circ}$ CPC - ha establecido excepcionalmente la posibilidad facultativa de eximirla del pago de las costas cuando "aparezca que ha tenido motivos plausibles para litigar". Para que ello suceda, deberá el juez manifestar dicha circunstancia expresamente (en tanto excepción) en su resolución, conclusión que se deriva del deber general de fundamentación de las sentencias definitivas, plasmado en el artículo 170 del CPC. Se trata de un paliativo de equidad a la regla "el que pierde paga", que a nuestro juicio debe ser examinado con más detalle ${ }^{69}$.

La discusión en torno a este concepto es de larga data, y se puede plantear en los términos que Chiovenda ya señalaba a comienzos del siglo pasado

¿Será justa la condena del vencido sólo por serlo, y por tanto también en pleitos en que concurriendo una posibilidad, por pequeña que sea, de discusión, no es posible dirigirle reproche alguno subjetivo; o será preferible la limitación que tuvo la condena en tiempos pasados y tiene todavía en algunas legislaciones, es decir, la limitación al caso de dolo o de culpa lata ${ }^{70}$ ?

Las dificultades que encierra la pregunta de Chiovenda, se ven reflejadas en la experiencia reciente del sistema italiano, en la cual la jurisprudencia históricamente interpretaba de manera amplia la excepción de los motivos plausibles para litigar. Ante esto, el año 2009 el legislador decidió (modificando el artículo 92 del Código de Procedimiento Civil italiano) restringir la aplicación de la excepción para "casos graves y excepcionales", indicados explícitamente en la sentencia, con la intención de que los tribunales justifiquen su decisión de no aplicar la regla general del que pierde paga, y lo reserven solo para casos calificados ${ }^{71}$. Posteriormente, se modificó nuevamente la norma, estableciendo que el tribunal puede distribuir las costas en casos de novedad absoluta del asunto tratado o cambio de jurisprudencia sobre la materia del juicio $^{72}$. Sin embargo, recientemente el Tribunal Constitucional italiano declaró inconstitucional esta restricción, sosteniendo que se pueden compensar total o parcialmente las costas no solo en estas hipótesis, sino también "cuando existen otras razones serias y excepcionales similares"73. Como se ve, pese a los intentos iniciales del legislador por limitar la aplicación de la excepción de los motivos plausibles para litigar, tanto las reformas legislativas introducidas

\footnotetext{
${ }^{69}$ Ello sin perjuicio de los casos excepcionales en los que el legislador expresamente establece la condena en costas del demandado sin considerar de modo alguno la conducta de las partes, como en el artículo 569 inciso final del CPC (denuncia de obra nueva), o el artículo 2334 del Código Civil (acciones populares), siendo este último caso particularmente interesante al otorgarse todas las costas al demandante bajo el solo requisito que las acciones "parecieren fundadas".

70 CHIOVENDA (2004), p. 106.

${ }^{71}$ DE LUCA (2012), pp. 185-186.

72 Decreto Ley N ${ }^{\circ} 132 / 2014$, convertido en Ley $N^{\circ} 162 / 2014$.

${ }^{73}$ Corte Costituzionale, 77/2018, de 7 de marzo de 2018.
} 
como las decisiones jurisprudenciales han terminado por ampliar la aplicación de la referida excepción, acercándose con ello la regulación a la posición históricamente mantenida.

Entre nosotros, debemos analizar en primer término qué se ha entendido por parte de la doctrina y la jurisprudencia como "motivo plausible para litigar", para posteriormente analizar la conveniencia de mantener dicha regla de cara a una futura reforma al proceso civil. En cuanto al concepto mismo de "motivos plausibles para litigar", se entiende que estos concurren cuando estamos en presencia de circunstancias muy calificadas; el litigante vencido totalmente ha actuado movido por circunstancias de entidad e importancia ${ }^{74}$. Para Casarino, por su parte, motivo plausible para litigar es sinónimo de "circunstancias calificadas que han motivado a las partes a litigar por estimar fundadamente, que sus acciones o excepciones tenían base legal"75. En un sentido similar, para Cortez y Palomo, la expresión denota "que el vencido haya actuado movido por circunstancias de entidad e importancia, sin que baste la mera ausencia de dolo o culpa"76. Al respecto, han sostenido dichos autores que estos motivos plausibles deben aparecer en los mismos autos, asunto que el tribunal debe juzgar en cada caso ${ }^{77}$. En cambio, Rodríguez plantea una interpretación distinta, sosteniendo que la parte derrotada no ha tenido motivo plausible para litigar solo "cuando su pretensión ha sido temeraria"78. Bajo esta lectura, tener motivo plausible constituiría la regla general, y solo excepcionalmente, bajo una hipótesis de conducta temeraria del litigante procedería la condena en costas del demandado ${ }^{79}$. En este sentido, ¿necesariamente una demanda que carece de motivos plausibles es una demanda temeraria? ¿Son términos equivalentes, o podría existir una demanda sin motivos plausibles para litigar que a su vez no sea temeraria?

Sobre esta materia, se advierte una falta de regulación y poca claridad en la doctrina y jurisprudencia ${ }^{80}$ chilena, lo que incide directamente en la aplicabilidad de la condena en costas. En este sentido, el motivo plausible para litigar constituye la válvula de control del sistema de distribución de costas en Chile, que permite pasar de la regla inglesa (sistema al que formalmente adhiere el CPC) a la regla estadounidense. Por una parte, si se adopta un criterio blando de interpretación de los motivos plausibles para litigar, denegando la existencia de estos solo en caso de conducta temeraria del litigante, ello conduce en la práctica a la consagración de la regla estadounidense, según la cual cada una de las partes debe soportar sus costas personales salvo que se acredite la mala fe del litigante, como hemos visto. Por otra parte, la ausencia de una regla clara al respecto deja al completo arbitrio del tribunal la condena en costas, lo cual nos parece riesgoso. Como señalaba Chiovenda, en esta materia "el remedio debe darlo el legislador, no la buena voluntad del juez" ${ }^{\prime 1}$.

\footnotetext{
${ }^{74}$ STOEHREI (2007), p. 57.

${ }^{75}$ CASARINO (2005), p. 172.

${ }^{76}$ CORTEZ y PALOMO (2018), p. 437.

77 CORTEZ Y PALOMO (2018), p. 437.

78 RODRÍGUEZ (2013).

${ }^{79}$ Sobre este punto, resulta interesante tener en cuenta lo dispuesto en el artículo 50 E de la Ley N ${ }^{\circ} 19.496$, de 1997, que contempla la posibilidad que el juez declare que una denuncia, querella o demanda interpuesta sea declarada como "temeraria", agregando que ello ocurre en caso que "carezca de fundamento plausible". La norma permite además imponer sanciones disciplinarias para el abogado.

${ }^{80}$ Por ejemplo, en la sentencia de Corte de Apelaciones de Concepción, Rol N 816-2016, de 20 de septiembre de 2016 , ha señalado de manera un tanto ambigua que la expresión "motivos plausibles", "importa que el juez en cada caso particular deberá ponderar todos y cada uno de los hechos que conforman el proceso, y si estos los encuentra atendibles, admisibles o recomendables procederá a eximir de las costas al vencido por considerar que en el caso sublite este ha tenido motivos plausibles para litigar, de manera que, tal determinación dependerá de la conducta procesal de la parte vencida" (c. 43). Asimismo, como se ha resuelto, la exención del pago de costas por haber tenido motivo plausible para litigar no obsta que todas las excepciones opuestas por el litigante vencido hayan sido desestimadas. Corte de Apelaciones de La Serena, 14 junio 1918.

${ }^{81}$ CHIOVENDA (2004), p. 109.
} 


\subsection{Otras causales de exención del pago de costas}

\section{a) El voto disidente como causal de eximición del pago de costas}

La legislación chilena establece una regla especial para el caso de que el fallo haya sido pronunciado por un tribunal colegiado. El artículo 146 CPC señala que no podrá condenarse al pago de las costas al vencido, cuando la resolución no haya sido acordada de manera unánime por los miembros del tribunal colegiado. Concurriendo al menos uno de los votos a favor del perdedor, el tribunal deberá ${ }^{82}$ eximir al litigante vencido del pago de las costas. Para Casarino ${ }^{83}$, dicha regla obedece a una concretización del criterio de vencimiento total en tanto en este caso,

los motivos plausibles para litigar están establecidos implícitamente en el mismo fallo, desde el momento en que ese litigante no ha sido vencido totalmente por los votos conformes de la unanimidad del tribunal. Es evidente que el solo hecho de haber obtenido uno o más votos en su favor, demuestra que había cierto fundamento para mantener una acción o excepción en las condiciones señaladas.

Discrepamos de dicha interpretación. Si bien la presencia de motivos plausibles para litigar puede de hecho manifestarse en un voto disidente que acoja la tesis del litigante derrotado, ello no siempre será así. El voto disidente puede hacer referencias no a la plausibilidad de la tesis contraria a la aceptada por la mayoría, sino más bien - por ejemplo- a defectos formales del recurso $u$ otros vicios de carácter procedimental no relacionados con una argumentación de fondo. En consecuencia, dependerá de los motivos esgrimidos en el voto disidente el calificar dicha circunstancia como motivo suficiente para litigar.

\section{b) Exención de costas en segunda instancia}

El artículo 145 CPC contiene otra excepción, al permitir facultativamente al tribunal de alzada eximir a la parte vencida de la obligación de pagar las costas del recurso a la parte contra quien se dicte la sentencia (unánime), expresando motivos especiales para ello. Esta causal permite flexibilizar la imposición de la condena en costas respecto del recurrente derrotado, en base a la existencia de "motivos especiales". Sin embargo, al igual que con la expresión "motivos plausibles", estamos en presencia de un concepto jurídico indeterminado, no definido por el legislador, dejando al completo arbitrio de los tribunales determinar en qué casos resulta procedente eximir a la parte vencida del pago de las costas del recurso. Si bien la ausencia de una regla no es de por sí problemática, el legislador sí podría indicar criterios más objetivos mediante los cuales los tribunales puedan sustentar su decisión de eximir del pago de costas. Así, por ejemplo, el legislador podría indicar que se podrá eximir del pago de costas al litigante que haya fundado su recurso en la jurisprudencia de al menos tres resoluciones dictadas por tribunales superiores de justicia, o algún otro criterio análogo ${ }^{84}$.

\section{c) El privilegio de pobreza como causal de eximición del pago de costas}

Por último, el artículo 600 del Código Orgánico de Tribunales estatuye en su inciso $3^{\circ}$ la última excepción, que mira derechamente las facultades económicas de las partes: "Las personas que gocen de privilegio de pobreza no serán condenadas al pago de costas, a menos que el tribunal respectivo, en resolución fundada, declare que han obrado como litigantes temerarios o maliciosos". Al respecto, la citada disposición establece una exigencia al juez para

\footnotetext{
82 Para Stoehrel esto es facultativo. STOEHREL (2007), p. 57.

${ }^{83}$ CASARINO (2005), p. 172.

${ }^{84}$ Lo anterior no obsta a que sean los propios tribunales, mediante el desarrollo de la jurisprudencia, quienes elaboren estos criterios ante el silencio del legislador.
} 
el evento que, gozando una de las partes del beneficio de pobreza, estime pertinente su condena en costas, situación en la que el tribunal - como se ha resuelto-deberá "asentar previamente el hecho de la temeridad o malicia con la que dicho litigante ha obrado en la tramitación del proceso" $\$$.

\section{La tasación de las costas personales}

La obligación que impone el pago de las costas es una obligación ilíquida. Por lo tanto, para que su pago pueda ser exigido judicialmente es necesario - como cuestión previaproceder a su liquidación. Para ello, el legislador ha procurado por medio de la regulación contenida en los artículos 138 y ss. del CPC establecer criterios más o menos objetivos, que permiten por medio del empleo de parámetros normativos, determinar el monto que las costas a pagar alcanzarán ${ }^{86}$. Ello se efectúa por medio del procedimiento establecido en el artículo 138 y ss. del CPC, denominado "tasación y regulación de costas".

Para efectos de calcular el monto al que ascienden las costas, el legislador distingue entre costas procesales y personales (artículo 139 del CPC). Las costas procesales, esto es, aquellas que son causadas en la formación del proceso y que corresponden a servicios estimados por los aranceles judiciales, se determinan en base a dichos aranceles, referidos a las costas procesales útiles, previamente estampados o consignados en autos ${ }^{87}$. Su tasación es entonces mecánica, limitándose a aquellas actuaciones realizadas con motivo del proceso en curso, cuyo costo se encuentra previamente indicado por medio de estampados efectuados por los funcionarios a cargo de la realización de dichas diligencias durante el transcurso del proceso. Como se ha sostenido, "para avaluar las costas procesales bastará con examinar las diligencias de que se trata y ver en cuanto están estimadas en los aranceles judiciales respectivos" 18 . De este modo, si por ejemplo el receptor omitió estampar en autos el monto cobrado por una determinada diligencia, el juez no podrá suplir dicha omisión por medio de su voluntad.

Por su parte, las costas personales son - de acuerdo al artículo 139 del CPC- aquellas provenientes fundamentalmente de los honorarios de los abogados y demás personas que hayan intervenido en el negocio. Los honorarios de los abogados, como base del pago de costas, se regularán - prosigue la disposición citada - en base al arancel fijado por el Colegio de Abogados. A diferencia de lo que sucede con las costas procesales, la regulación de las costas personales queda en la práctica entregada al criterio del tribunal ${ }^{89}$. En efecto, desde el fin de la colegiatura obligatoria dichos aranceles no rigen ${ }^{90}$. Por medio de la reforma introducida por el D.L. $N^{\circ} 3621$ de 1981, el Colegio de Abogados ha perdido parte importante de sus antiguas atribuciones, entre las cuales se encuentra la referida colegiatura obligatoria. A su vez, el artículo $5^{\circ}$ del D.L. N 2757 de 1971 derogó la facultad de los Colegios Profesionales para fijar aranceles de honorarios, dejando sin efectos los ya vigentes ${ }^{91}$.

Encontrándose entonces tácitamente derogada la regla que establece la forma de regular los honorarios de los abogados, la determinación del monto a pagar por concepto de costas personales corresponde a un problema de difícil solución. Como veremos a continuación, la inexistencia de estudios doctrinarios sobre el tema, sumado a una jurisprudencia vacilante, han convertido la regulación de las costas personales en una cuestión imprevisible para los litigantes,

\footnotetext{
${ }^{85}$ Corte de Apelaciones de Santiago, Rol N 1580-2016, de 28 de septiembre de 2016.

${ }^{86}$ Véase ROMERO (2017), p. 231.

${ }^{87}$ En un sentido similar, el Proyecto de Código Procesal Civil establece en su artículo 46: "Alcance de las costas. Se consideran costas todos los tributos, tasas, derechos, honorarios de abogados, procuradores, peritos, depositarios, tasadores, auxiliares del tribunal y demás gastos que se hayan efectuado con motivo de actuaciones realizadas dentro del proceso".

88 CASARINO (2005), p. 174.

${ }^{89}$ CASARINO (2005), p. 174.

90 STOEHREL (2007), p. 59.

${ }^{91}$ Sin perjuicio de ello, alguna jurisprudencia reciente ha señalado que los honorarios de los abogados "se regularán de acuerdo al arancel fijado por el respectivo Colegio Provincial de Abogados y, a falta de este, por el Consejo General del Colegio de la Orden". Corte de Apelaciones de Concepción, Rol N 442-2012, de 24 de septiembre de 2012 (c. 4).
} 
sujeta a criterios difícilmente reconducibles a estándares concretos que permitan dotar de legitimidad a la decisión. Día a día, al regular las costas personales, los tribunales desarrollan su función "a oscuras", con escasa fundamentación y sin criterios previamente fijados que permitan predecir el costo de ser derrotado en juicio. De acuerdo a Rodríguez, en la inmensa mayoría de los casos, "la tasación de las costas dista mucho de la realidad, de suerte que la víctima de un juicio aventurado experimentará siempre un perjuicio, a veces monetariamente cuantioso y grave para la imagen personal o corporativa del afectado". Concluye dicho autor señalando que "no parece justo que quien es arrastrado a los tribunales de justicia, sin razón suficiente que lo justifique, deba experimentar un daño irremediable, cualquiera que sea el resultado de la litis"92.

El objetivo de la regulación sobre costas debiese precisamente -como sostiene la doctrina alemana - propender hacia la justicia en la imposición de los costes del proceso. De este modo, cada parte del proceso civil debiese tener anticipadamente claridad respecto al modo en el cual se distribuye el riesgo que significa una derrota procesal, determinación para la cual influirá la perspectiva de éxito que estime la parte su posición jurídica alcanzará ${ }^{93}$. Sobre este punto, también debe tenerse en cuenta la necesidad de tener reglas claras, de manera tal que el sistema judicial otorgue incentivos para reducir los costos totales de la litigación ${ }^{94}$.

Como un primer acercamiento, nos parece que la determinación de las costas personales debiera intentar, en la mayor medida de lo posible, acercarse a la suma precisa de gastos en que la parte vencedora efectivamente incurrió. Siendo ello así, los tribunales debieran examinar de cerca la rendición de todos los gastos en que incurrió la parte demandante. Por otra parte, en caso que la demandante haya acordado un pacto de cuota litis con sus abogados, sería un antecedente que permitiría al tribunal determinar con mayor precisión el monto de los honorarios de los abogados. Sin embargo, ninguna de estas consideraciones se encuentra presente en la jurisprudencia que hemos analizado.

La Corte de Apelaciones de Valparaíso, mediante sentencia dictada el año 2007, entregó distintas directrices para calcular judicialmente el monto que alcanzan las costas en un caso concreto. A este respecto, sostuvo el tribunal de alzada que al no existir actualmente disposiciones o reglas expresas que reglamenten la forma o manera de regular los honorarios profesionales de los abogados, y para los efectos de obtener un adecuado cálculo del monto que deberá establecerse a favor de la demandada, los sentenciadores tienen facultades para decidir recurriendo a principios de equidad.

Al respecto, se sostuvo que los criterios a considerar en el cálculo de los honorarios a pagar a título de costas personales consideran diversos factores, entre los cuales enumera

la naturaleza de la labor profesional llevada a cabo, la importancia de los escritos presentados, el estado procesal de la causa principal en que se interpone el incidente, el estudio realizado por el profesional, la importancia del juicio principal, el trabajo desplegado por el profesional, los recursos deducidos, el tiempo transcurrido entre la condena en costas y la fijación de estas, el número de escritos útiles, la experiencia y reputación del profesional que ha intervenido en el incidente, la capacidad económica de las partes condenada en costas, la importancia del asunto, el tiempo probable dedicado a tal tarea y la labor requerida para desempeñarla, la trascendencia y dificultad de lo litigado, el monto pecuniario involucrado, el número e importancia de los incidentes y el beneficio para el cliente.

\footnotetext{
92 RODRÍGUEZ (2013).

${ }^{93}$ BAUMBACH et al. (2018), Par. 91, Rdn. 10, Hartmann. El mismo punto es planteado respecto al derecho inglés en PEYSNER (2009), pp. 162-163, sosteniendo que la impredictibilidad de las costas es contraria al acceso a la justicia. ${ }^{94}$ POSNER (2007), pp. 634 y ss.
} 
Al respecto, concluye el tribunal señalando que "si bien la cuantía de lo disputado es un factor a considerar para la regulación de las costas personales, no es el único" ${ }^{\prime 95}$. Sobre este último punto, llama la atención que la Corte no tome en consideración si la contratación de los servicios de abogados por parte del demandante se realizó o no mediante el referido pacto de cuota litis, pacto que en definitiva asegura la remuneración del abogado (y por lo tanto las costas personales) sobre la base de un porcentaje del resultado del juicio.

Atribuyendo una función netamente indemnizatoria, la Corte de Apelaciones de Concepción ha resuelto que considerar la indemnización como completa, "implica que debe cubrir todos los gastos causados al expropiado, entre ellos los costos que hubo de efectuar para procurarse una defensa técnica-jurídica de frente al acto de autoridad que lo afectó". El expropiado debió recurrir al tribunal para la legítima defensa de sus derechos e intereses, y ello, "desde una perspectiva de racionalidad y justicia, debe ser de cargo de quien emana dicho acto de autoridad"96. En un sentido similar, la Corte de Antofagasta ha resuelto que para los efectos de regular los honorarios profesionales de los abogados, incide como factor a considerar, en primer lugar, la cuantía del juicio, y además la consideración a circunstancias tales como la

prudencia y equidad, naturaleza y complejidad de la labor profesional, el trabajo desplegado por el profesional, los recursos deducidos, el número de escritos útiles, el tiempo factible dedicado a la causa, la trascendencia y dificultad de lo litigado, el monto pecuniario involucrado, el número e importancia de los incidentes, como también la capacidad económica de las partes condenadas en $\operatorname{costas}^{97}$.

Por su parte, la Corte de Temuco ha sostenido al respecto que como elementos objetivos para determinar las costas, se pueden utilizar diversos parámetros como lo son a título meramente enunciativo,

la complejidad del asunto debatido, el éxito obtenido, la importancia del caso, la novedad o dificultad de los problemas jurídicos discutidos, la experiencia de los letrados, así como también los aranceles correspondientes a la Defensoría Penal Pública y al Colegio de Abogados ${ }^{98}$.

La Corte de Coyhaique sostiene que "regular el monto que debiera corresponder (por concepto de costas personales), en base a la cuantía de lo disputado, no aparece justo ni equitativo para el demandado que fue (...) negligentemente representado"99. Al momento de considerar excesiva la condena en costas impuesta en incidente especial, la Corte Suprema sostuvo como criterios para determinar dicho exceso "la naturaleza e importancia del incidente y la actividad desplegada por la parte que en él obtuvo"100.

Como puede apreciarse a partir del examen de estas sentencias, los tribunales aprecian las costas personales de forma un tanto intuitiva, indicando algunos parámetros flexibles, pero siempre mencionando como criterios fundamentales la "prudencia" y "equidad". A nuestro juicio, se trata de criterios insuficientes. Por otra parte, nos parece indispensable que los tribunales tengan en cuenta las consideraciones enunciadas al comienzo de esta sección, en torno a examinar con mayor precisión las labores efectivamente desplegadas por los abogados y expertos contratados durante la tramitación del litigio, ya que la condena en costas debiera reflejar, bajo una perspectiva resarcitoria, únicamente los gastos en que efectivamente incurrió la parte vencedora.

\footnotetext{
${ }_{95}$ Corte de Apelaciones de Valparaíso, Rol N²016-07, de 21 de abril de 2008; y Corte de Apelaciones de Valparaíso, Rol N²017-07, de 21 de abril de 2008.

${ }^{96}$ Corte de Apelaciones de Concepción, Rol N 1163-2015, de 15 de noviembre de 2016.

${ }^{97}$ Corte de Apelaciones de Antofagasta, Rol Nº 823-2013, de 2 de junio de 2014.

${ }^{98}$ Corte de Apelaciones de Temuco, Rol N 513-2016, de 10 de junio de 2016.

${ }^{99}$ Corte de Apelaciones de Coihaique, Rol No 183-2011, de 23 de diciembre de 2011.

${ }^{100}$ Corte Suprema, Rol N 8877-1989, de 7 de septiembre de 1989.
} 
En esta materia, la experiencia comparada puede resultar útil. Así, a modo de ejemplo, el derecho estadounidense establece que, en aquellos casos en los cuales el litigante vencedor tiene la posibilidad de reclamar costas personales, el tribunal debe revisar tanto las horas como la tarifa a cobrar por los abogados del litigante. De tal manera que las "horas consideradas excesivas, innecesarias, ineficientes o excesivas son reducidas" por el tribunal ${ }^{101}$. En el mismo sentido, la Ley de Enjuiciamiento Civil de España establece una limitación cuantitativa interesante en su artículo $394 \mathrm{~N}^{\circ} 3$, al disponer que si se imponen costas al litigante vencido,

éste sólo estará obligado a pagar, de la parte que corresponda a los abogados y demás profesionales que no estén sujetos a tarifa o arancel, una cantidad total que no exceda de la tercera parte de la cuantía del proceso, por cada uno de los litigantes que hubieren obtenido tal pronunciamiento.

Lo mismo puede concluirse a partir del estándar de proporcionalidad que se impone en el derecho inglés, señalado más arriba (supra 3.1) ${ }^{102}$. Por otra parte, en cuanto a la determinación de la tarifa, los tribunales toman en cuenta, entre otros factores, la complejidad del caso, las habilidades requeridas para el asunto en cuestión, la calidad de los servicios jurídicos proporcionados, la tarifa que se acostumbra a pagar por trabajos similares en la comunidad jurídica, y la experiencia, reputación y habilidad de los abogados ${ }^{103}$.

\section{A modo de conclusión: breve crítica al estado actual de la regulación legal}

A la luz de la experiencia adquirida de la aplicación del Título XIV del CPC por parte de los tribunales, debe llegarse a la conclusión que la regulación vigente ha quedado absolutamente desfasada y merece ser revisada. En primer término, las disposiciones vigentes corresponden en su mayoría a reglas imprecisas, contradictorias entre sí y que no se condicen con un criterio claro y unívoco de asignación del costo de litigar. Por otro parte, hoy en día, las disposiciones mismas y la forma de aplicarlas hacen que el litigante de mala fe no sufra el costo real que significa la interposición de acciones temerarias, y recursos e incidentes dilatorios, porque el monto de lo que puede ser condenado a pagar por ello es insignificante y no se atiene a la realidad ${ }^{104}$.

Desde este punto de vista, la regulación de las costas debiera avanzar hacia un sistema que, sobre todo, permita el acceso a la justicia de cualquier persona para hacer valer sus pretensiones, asegurando así el ejercicio de la función jurisdiccional como mecanismo idóneo para la resolución de controversias jurídicas. Pero, asimismo, la regulación debiera incentivar a no incurrir en conductas ineficientes que aumenten el costo social de la litigación y sobrecarguen los órganos jurisdiccionales, y al mismo tiempo impedir que las partes utilicen el proceso como mero mecanismo de especulación o de presión a la contraparte.

Las reglas claras al respecto permiten cumplir estos objetivos. En tal sentido, se requiere en primer lugar mayor certeza al momento de determinar en qué consisten los llamados motivos plausibles para litigar que eximen de la condena en costas y posiblemente, analizar si dicho criterio debe seguir constituyendo la cláusula de eximición de costas para el litigante vencido. Ya hemos visto que una interpretación blanda sobre ello implica en la práctica una alteración radical de la regla "el que pierde paga". Entendemos que se trata de un asunto controvertido y de difícil resolución, pero nos parece necesaria una regla más clara o un principio con criterios más precisos.

\footnotetext{
101 HERR et al. (2013), p. 820

102 Las Civil Procedure Rules, de 1998, §44.3, identifican cinco factores para determinar la proporcionalidad de las costas: (a) la cuantía del litigio, (b) el valor de algún remedio no-dinerario del litigio, (c) la complejidad de la litigación, (d) cualquier trabajo adicional que haya generado la conducta de la parte vencida y (e) cualesquiera otros factores involucrados en el procedimient o, como la reputación o importancia pública.

103 HERR et al. (2013), pp. 820-821.

${ }^{104}$ MARTÍNEZ (1999).
} 
En segundo lugar, ante la inexistencia en nuestro sistema de aranceles profesionales, debe revisarse la tasación de las costas personales, actualmente devenida en una práctica errática y dispar, carente de un criterio común. Cualquier abogado que litigue en los tribunales puede constatar que las más de las veces resulta dicha tasación irrisoria por lo exigua y en otros pocos casos, excesiva ${ }^{105}$. Debe buscarse un sistema que fije pautas legales para que los tribunales tengan determinados parámetros a los cuales acudir para ello, como puede ser la cuantía del asunto, junto con su mayor o menor dificultad ${ }^{106}$, o los criterios que provee la experiencia comparada. Adicionalmente, resulta llamativo que en la tasación de las costas no se tomen cuenta las consideraciones apuntadas más arriba en torno a las funciones que deben desempeñar las costas, considerando los efectos que tiene en los costos sociales el ejercicio de acciones jurisdiccionales y el acceso a la justicia. Tampoco se presta atención a si los servicios de los abogados fueron o no contratados bajo un pacto de cuota litis o aún más relevante, al monto de los honorarios efectivamente pagados por cada parte.

Como hemos visto, las costas desempeñan una doble función resarcitoria pero a la vez sancionadora. Ambas finalidades son relevantes, puesto que la función resarcitoria asegura el acceso a la justicia y garantiza el derecho de las víctimas a ser reparadas íntegramente. Por otra parte, la función sancionatoria genera verdaderos disuasivos para aquellos litigantes que muchas veces a sabiendas de la implausibilidad de su acción, deciden poner en marcha el aparato jurisdiccional del Estado, con el enorme gasto de recursos públicos y privados que ello representa. Implementar estas funciones de un modo eficaz, corresponde a una tarea urgente de parte del legislador.

\section{BIBLIOGRAFÍA CITADA}

Abeliuk Manasevich, RenÉ (2014): Las Obligaciones, 6ạ edición (Santiago, Thomson Reuters), tomo II.

ANDERSON, DAVID A. (1994): "Improving Settlement Devices: Rule 68 and beyond", en: The Journal of Legal Studies (Vol. 23), pp. 225-246.

ANDREWS, NeIL (2019): Andrews on Civil Processes. Court Proceedings, Arbitration \& Mediation, 2a edición (Cambridge, Intersentia).

BarRos Bourie, EnRIQUe (2017): "Fuerza económica y abuso de posición de debilidad de la contraparte en el desarrollo jurisprudencial y doctrinario del derecho de contratos", en: Corral Talciani, Hernán y Manterola Domínguez, Pablo (Eds.), Estudios de Derecho Civil XII (Santiago de Chile, Thomson Reuters), pp. 289-310.

Baumann, FloRian y Friehe, Tim (2012): “Contingent Fees Meet the British Rule: An Exploratory Study", en: Public Choice (Vol. 150), pp. 499-510.

Baumbach, Adolf; lauterbach, Wolfgang; Albers, Jan y Hartmann, Peter (2018): Zivilprozessordnung: ZPO, 76a edición (Munich, C.H. Beck).

CARRETA MuÑOZ, FRANCESCO (2008): "Deberes procesales de las partes en el proceso civil chileno: "Referencia a la buena fe procesal y al deber de coherencia", en: Revista de Derecho (Vol. XXI, $\mathrm{N}^{\circ} 1$ ), pp. 101-127.

CASARIno Viterbo, Mario (2005): Manual de Derecho Procesal, Derecho Procesal Civil (Santiago de Chile, Editorial Jurídica), tomo III.

CHIOVEndA, GIUSEPPE (2004): Condena en costas (Buenos Aires, VE Valletta Ediciones).

105 “[L]a percepción generalizada es que los jueces, cuando condenan en costas, lo que solo ocurre cuando una parte resulta enteramente vencida, las fijan en cifras muy inferiores a las reales". VARGAS et al. (2001), p. 154.

106 MARTÍNEZ (1999). 
Couture, EduARdo J. (2003): Estudios de Derecho Procesal Civil, 3ạ edición (Buenos Aires, Lexis Nexis), tomo III.

Cortez, Gonzalo y Palomo, Diego (2018): Proceso Civil. Normas comunes a todo procedimiento e incidentes (Santiago de Chile, Thomson Reuters).

De LUCCA, AlessandRa (2012): "Italy: A Tale of Successful Resistance?", en: Reimann, Mathias (Ed.), Cost and Fee Allocation in Civil Procedure (Dordrecht, Springer), pp. 185-194.

EhrenzWeig, Albert A. (1966): "Reimbursement of Counsel Fees and the Great Society", en: California Law Review (Vol. 54 N² 2), pp. 792-800.

FINNIS, JOHN (2000): Ley natural y derechos naturales (Traducc. Cristóbal Orrego Sánchez, Buenos Aires, Abeledo-Perrot).

GoldberG, John C.P.; Sebok, ANTHONY J. y ZIPURSKY, BENJAMIN C. (2016): Tort Law: Responsibilities and Redress, 4a edición (New York, Wolters Kluver).

Greenberger, Howard (1964): "The Cost of Justice: An American Problem, an English Solution", en: Villanova Law Review (Vol. 9, №3), pp. 400-414.

HerR, DAVID F.; HAydock, Roger S. Y Stempel, JefFrey W. (2013): Fundamentals of Litigation Practice (Minnesota, Thomson Reuters).

HODGES, CHRISTOPHER (2010): The Costs and Funding of Civil Litigation. A Comparative Perspective (Oxford, Hart Publishing).

JAUERNIG, OTHMAR (2007): Zivilprozessrecht, 29ạ edición (Munich, C.H. Beck).

KATZ, AVERY (1987): "Measuring the Demand for Litigation: Is the English Rule Really Cheaper?", en: Journal of Law, Economics \& Organization (Vol. 3, № 2), pp. 143-176.

(1990): "The effect of frivolous lawsuits on the settlement of litigation", en: International Review of Law and Economics (Vol. 10), pp. 3-27.

KuenZel, CAlVIn A. (1963): “The Attorney's Fee: Why Not a Cost”, en: lowa Law Review (Vol. 49), pp. 75-87.

MARTínez, Eustaquio (1999): “Las costas judiciales”, en: Revista del Abogado (№17). Disponible en:

https://archivo.colegioabogados.cl/cgibin/procesa.pl?plantilla=/v2/cont_revista.html\&idcat=32\&id_cat=7\&id_art=41\&nseccion=\%25 BFPor\%2520Qu\%25E9\%2520Asociarse\%253F\%2520\%253A\%2520Revista\%2520del\%2520Abog ado\%2520\%253A\%2520Revista\%2520N\%25BA\%252017\%2520\%253A\%2520TEMAS [visitado el 6 de marzo de 2020].

MAXEINER, JAMES R. (2010): “Cost and Fee Allocation in Civil Procedure", en: The American Journal of Comparative Law (Vol. 58), pp. 195-221.

Mery, Rafael (2010): "Tasas judiciales: Una alternativa para la justicia chilena", en: Latin American and Caribbean Law and Economics Association (ALACDE) Annual Papers. Disponible en: https://escholarship.org/uc/item/9bg8002m [visitado el 6 de marzo de 2020].

NúÑEz OJedA, RAúl y CARRASCo Delgado, Nicolás (2015): “Análisis económico de la administración de justicia: ¿La justicia como bien público o privado?”, en: Revista Chilena de Derecho (Vol. 42, $\mathrm{N}^{\circ} 2$ ), pp. 595-613.

Núñez Ojeda, Raúl y Pérez Ragone, Álvaro (2013): Manual de Derecho Procesal Civil, Parte General (Santiago de Chile, Thomson Reuters).

Peysner, JoHn (2009): "A Blot on the Landscape", en: Dwyer, Déirdre (Ed.), The Civil Procedure Rules Ten Years On (Oxford, Oxford University Press), pp. 157-170. 
POSNER, RICHARD (2007): Economic Analysis of Law, 7ạ edición (New York, Aspen Publishers).

PRIEST, GeORGE L. (1982): "Regulating the Content and Volume of Litigation: An Economic Analysis", en: Supreme Court Economic Review (Vol. 1), pp. 163-183.

ReImann, Mathias (2012): "Cost and Fee Allocation in Civil Procedure: A Synthesis", en: Reimann, Mathias (Ed.), Cost and Fee Allocation in Civil Procedure (Dordrecht, Springer), pp. 3-56.

Rodriguez, Pablo (2013): "Sobre las costas judiciales, Columna del diario El Mercurio del 24 de febrero de 2013". Disponible en: https://www.udd.cl/wp-content/uploads/2013/04/24-02-13elmer-COL-pablo-rodriguez.pdf [visitado el 21 de junio de 2019].

Romero Seguel, Alejandro (2017): Curso de Derecho Procesal Civil, 3a edición (Santiago de Chile, Thomson Reuters), tomo I.

SPIER, Kathryn E. (2007): "Litigation”, en: Polinsky, A. Mitchell y Shavell, Steven (Eds.), The Handbook of Law \& Economics (Amsterdam, Elsevier), pp. 259-342.

Stoehrel MAes, CARlos Alberto (2007): De las disposiciones comunes a todo procedimiento y de los incidentes, 6a edición (Santiago, Editorial Jurídica).

Vargas, Juan EnRique; PeÑa, Carlos y Correa, Jorge (2001): “El rol del Estado y el mercado de la justicia”, en: Cuadernos de Análisis Jurídicos ( $\left.N^{\circ} 42\right)$, pp. 1-176.

VARGO, JohN F. (1993): "The American Rule on Attorney Fee Allocation: The Injured Person's Access to Justice", en: The American University Law Review (Vol. 42), pp. 1567-1636.

\section{JURISPRUDENCIA CITADA}

BAHAMONDE (HERENCIA YACENTE) (1924): Corte Suprema 2 junio 1924 (casación forma), en: RDJ, T. XXII, Sec. 1a , pp. 1021 y ss.

LE FORT CON MUNICIPALIDAD DE IQUIQUE (1926): Corte Suprema 22 octubre 1926 (casación forma), en: RDJ, T. XXV, Sec. 1a , pp. 401 y ss.

VillaRroel y OtRos CON OSSIO (1939): Corte Suprema 4 diciembre 1939 (casación forma y fondo), en: RDJ, T. 37 Sec. 1a , pp. 477 y ss.

ROMÁN CON Bouzout (1947): Corte Suprema 14 enero 1947 (casación fondo), en: RDJ, T. XLIV, Sec. 1a ${ }^{a}$, pp. 444 y ss.

ORELLANA, JosÉ CON HENRÍQUeZ, MAXIMILIANO (1954): Corte Suprema 11 junio 1954 (casación forma y fondo), en: RDJ, T. LXI, Sec. 1'a, pp. 178 y ss.

EdWARDS C., JUAN Y OtROS CON GARCÉS R., ONOFRE Y OTROS (1954): Corte Suprema 14 septiembre 1954 (casación fondo), en: RDJ, T. LI, Sec. 1a a pp. 438 y ss.

Gormaz lopetegui, TeOdoro con Caja Nacional de Ahorros (1954): Corte Suprema 20 octubre 1954 (casación forma y fondo), en: RDJ, T. LI, Sec. 1a , pp. 509 y ss.

SCHIAPPACASE M., JUAN Y OTRO CON FISCO (1959): Corte Suprema 10 agosto 1959 (casación forma y fondo), en: RDJ, T. LVI, Sec. 1á, pp. 258 y ss.

SOCIedAd Mimica Hnos con Müller, EnRIQUe (1960): Corte de Apelaciones de Santiago 16 diciembre 1960 (recurso de apelación), en: RDJ, T. LVII, Sec. 2a ${ }^{-}$, pp. 113 y ss.

CORPORACIÓN DE LA VIVIENDA CON LE-FORT B., CARLOS (1966): Corte Suprema 30 septiembre 1966 (reclamación indemnización), en: RDJ, T. LXIII, Sec 1a, pp. 348 y ss.

Fleishmann Distilling Corp. vs. MAIER BREWING Co. (1967): Corte Suprema de Estados Unidos 8 mayo 1967, 386 U.S. 714 (1967). 
GABRIEL D., LUIS CON CONTRERAS, SANTIAGO (1970): Corte Suprema 16 octubre 1970 (casación forma y fondo), en: RDJ, T. LXVII, Sec. 1a, pp. 455 y ss.

Alyeska PIPELINE SeRviCe Co. VS. WILDERNESS SoCIETY (1975): Corte Suprema de Estados Unidos 12 mayo 1975, 421 U.S. 240, 95 S. Ct. 1612, 44 L. Ed. 2d 141 (1975).

Mihalik VS. Pro ARTS INC. (1988): Corte de Apelaciones del Sexto Circuito 7 julio 1988, 851 F. 2d 790 (6 $6^{\text {th }}$ Cir. 1988).

Banco de Chile con Ministros de la Corte de Apelaciones de Punta Arenas (1989): Corte Suprema 7 septiembre 1989 (recurso de queja), en: CL/JUR/863/1989.

MÁRQUEZ BRIONES (1996): Corte Suprema 9 julio 1996 (casación en el fondo), en: CL/JUR/575/1996.

Ael Rediffusion Music Ltd v. Phonographic Performance Ltd (1999): Corte de Apelaciones de Inglaterra y Gales 19 febrero 1999, [1999] 1 WLR 1507.

POLLAK RINDLER CON SOCIEDAD INDEX SALUD LTDA. (2007): Corte Suprema 17 enero 2007 (casación en el fondo), en: CL/JUR/5689/2007.

BANCO DE CRÉDITO E INVERSIONES CON LAGOS Y LINCH LTDA. Y OTRO (2010): Corte de Apelaciones de Concepción 23 marzo 2011 (recurso de apelación), en: CL/JUR/9801/2011.

Fisco de CHILE CON CALDERón CRUZ (2011): Corte de Apelaciones de Coihaique 23 diciembre 2011 (recurso de apelación), en: CL/JUR/9059/2011.

Serviu Región del Bio Bio y otro con Sepúlveda Sanhueza (2012): Corte de Apelaciones de Concepción 24 septiembre 2012 (recurso de apelación), en: CL/JUR/2094/2012.

LAYHeR Del PACífICO S.A. CON TAMAYO SORDo (2013): Corte de Apelaciones de San Miguel 24 enero 2013 (recurso de apelación), en: CL/JUR/413/2013.

SOCIEDAd QuímicA Y MineRA DE CHILE S.A. CON SOCIEDAD LeGAL MineRA (2014): Corte de Apelaciones de Antofagasta 2 junio 2014 (recurso de apelación), en: CL/JUR/3616/2014.

CoventRY V. LAWRENCE (2015): Corte Suprema del Reino Unido 22 julio 2015, [2014] UKSC 46; [2015] AC 106.

Ministerio Público con Cofré Ferrada (2016): Corte de Apelaciones de Temuco 10 junio 2016 (recurso de apelación), en: CL/JUR/4093/2016.

GASTÓn MELLA CON INMOBILIARIA E INVERSIONES ALtOMONTE LIMITADA (2016): Corte de Apelaciones de Concepción 20 septiembre 2016 (recurso de apelación), en: CL/JUR/432/2016.

MILOR LHERISSE CON DISTRIBUIDORA CARBóN LISTO LIMITADA (2016): Corte de Apelaciones de Santiago 28 septiembre 2016 (recurso de nulidad laboral), en: CL/JUR/7470/2016.

Ministerio Público con Molinas ToRres (2016): Corte Suprema 17 octubre 2016 (recurso de apelación), en: CL/JUR/9939/2016.

BRuhn Hubricht con Consejo de DefenSA Del Estado (2016): Corte de Apelaciones de Concepción 15 noviembre 2016 (recurso de apelación), en: CL/JUR/9469/2016.

EXCALIBUR VentuRES LLC V TEXAS Keystone INC. (No 2) (2016): High Court de Inglaterra y Gales, de 18 noviembre 2016, [2016] EWCA Civ 114; [2017] 1 WLR 221.

Sociedad Chilena del Derecho de Autor con Comercializadora Carlos Guzmán (2016): Corte de Apelaciones de Concepción 9 diciembre 2016 (recurso de apelación), en: CL/JUR/9079/2016.

CORTE COstituzionale DE ITALIA 7 DE MARzo DE 2018, 77/2018, en: https://www.cortecostituzionale.it/actionSchedaPronuncia.do?anno=2018\&numero=77. 


\section{NORMAS JURÍDICAS CITADAS}

LEY N ${ }^{\circ} 17.336$, Ley de propiedad intelectual. Diario oficial, 2 de octubre de 1970.

LEY N 19.300, Ley de propiedad industrial. Diario Oficial, 9 de marzo de 1994.

LEY N ${ }^{\circ} 19.496$, Ley sobre protección de los derechos de los consumidores. Diario Oficial, 7 de marzo de 1997.

LEY 1/2000 de ENJUICIAMIENTO CIVIL De EsPañA. Boletín Oficial del Estado, 7 de enero de 2000.

Codice Civile Italiano. Gazzetta Ufficiale, 16 de marzo de 1942.

Civil Procedure Rules de InglaterRa y Gales. 17 de diciembre de 1998.

United StATES Code (U.S.C.) DE Estados Unidos, Office of the Law Revision Counsel of the U.S. House of Representatives, 2006. 